\title{
The marine bacteria Shewanella frigidimarina NCIMB400 upregulates the type VI secretion system during early biofilm formation
}

\author{
Denis Linares, ${ }^{1}$ Natacha Jean, ${ }^{2}$ \\ Perrine Van Overtvelt, ${ }^{1}$ Tassadit Ouidir, ${ }^{3}$ \\ Julie Hardouin, ${ }^{3}$ Yves Blache ${ }^{1}$ and Maëlle Molmeret ${ }^{1 *}$ \\ Université de Toulon, ${ }^{1}$ MAPIEM, EA4323, ${ }^{2}$ PROTEE, \\ EA3819, 83957 La Garde France. \\ ${ }^{3}$ UMR 6270 CNRS, Laboratoire Polymères, \\ Biopolymères, Surfaces, Université de Rouen, \\ Mont-Saint-Aignan F-76820, France.
}

\section{Summary}

Shewanella sp. are facultative anaerobic Gramnegative bacteria, extensively studied for their electron transfer ability. Shewanella frigidimarina has been detected and isolated from marine environments, and in particular, from biofilms. However, its ability to adhere to surfaces and form a biofilm is poorly understood. In this study, we show that the ability to adhere and to form a biofilm of S. frigidimarina NCIMB400 is significantly higher than that of Shewanella oneidensis in our conditions. We also show that this strain forms a biofilm in artificial seawater, whereas in Luria-Bertani, this capacity is reduced. To identify proteins involved in early biofilm formation, a proteomic analysis of sessile versus planktonic membrane-enriched fractions allowed the identification of several components of the same type VI secretion system gene cluster: putative Hcp1 and ImpB proteins as well as a forkhead-associated domain-containing protein. The upregulation of Hcp1 a marker of active translocation has been confirmed using quantitative reverse transcription polymerase chain reaction. Our data demonstrated the presence of a single and complete type VI secretion system in S. frigidimarina NCIMB400 genome, upregulated in sessile compared with planktonic conditions. The fact that three proteins including the secreted protein Hcp1 have been identified may suggest that this type VI secretion system is functional.
Introduction

The capacity of bacterial species to adhere and form a biofilm in situ and in vitro has been shown to vary depending on several factors such as gene expression at the time of adhesion, environmental conditions and types of surface involved. In the marine sector, ecological and economic consequences of biofilm and subsequent biofouling formation on immersed artificial surfaces are numerous, such as ship drag reduction or species relocation (Yebra et al., 2004). Several anti-biofilm strategies are being studied in virtually all industrial or medical sectors. The main difficulty in the marine environment is to find ecofriendly alternatives to limit biofilm development that would be non-toxic for other organisms. One of the potential straightforward strategy focuses on the inhibition of adhesion and the early step of biofilm formation on an inert surface. This could represent in combination with other strategies integrating for instance surface properties and structuration as well as other anti-biofilm molecules (targeting quorum sensing or c-di GMP regulatory networks), a way to limit biofilm and biofouling development on ship hull paints. Therefore, understanding the mechanism of adhesion and early biofilm formation of marine bacteria developing on inert surfaces is the first step toward the discovery of potential adhesion inhibitors that could be effective in marine conditions.

Shewanella sp. are facultative anaerobic Gramnegative, motile, rod-like bacteria frequently found and isolated in marine environments as are Pseudoalteromonas sp. or Vibrio sp. (Patel et al., 2003; Stin et al., 2003; Huggett et al., 2006; Hau and Gralnick, 2007; Fredrickson et al., 2008; Brian-Jaisson et al., 2014; Doghri etal., 2015). The Shewanella frigidimarina NCIMB400 strain, a marine isolate, was originally referred to as Pseudomonas-like marine bacteria then as Shewanella putrefaciens prior to re-classification. Shewanellae in particular Shewanella oneidensis MR-1, a fresh water isolate have been extensively studied for their ability of electron transfer, with the utilization of a broad array of final electron acceptors in anaerobic conditions (Lee et al., 1977; Reyes-Ramirez et al., 2003; Paquete et al., 2010). Because of their diverse metabolic abilities such as carbon cycling, remediation, microbial fuel cells, Shewanella sp. are able to survive in diverse 
environments and they have been isolated from habitats characterized by diverse salt concentrations, temperatures and barometric pressures (reviewed in $\mathrm{Hau}$ and Gralnick, 2007). Since its first isolation in grease ice and the ice-free zone in Antarctica (Bowman et al., 1997), detection by microarray analysis and isolation of S. frigidimarina strains have been performed from marine biofilm samples (Patel et al., 2003; Stin et al., 2003; Brian-Jaisson et al., 2014; Doghri et al., 2015). Overall, little data are available on $S$. frigidimarina ability to adhere and form biofilm on surfaces, in contrast with its freshwater counterpart S. oneidensis MR-1 (Vanrobaeys et al., 2003; Thormann et al., 2004; De Vriendt et al., 2005; Learman et al., 2009; Kouzuma et al., 2010; Zhang et al., 2010).

Bacteria are capable of expressing a whole set of diverse adhesins on their surface, such as fimbrial adhesins (i.e. Type IV pili), curli and non-fimbrial adhesins (i.e. integral outer membrane adhesins) and secreted adhesins. Expression of these proteins, which can play a role in adhesion and biofilm formation, can differ in function of species or strains, environmental conditions and surfaces (reviewed in Gerlach and Hensel, 2007). In this study, we have examined adhesion and biofilm formation of $S$. frigidimarina NCIMB400 in comparison with that of S. oneidensis MR-1. A two-dimensional (2D) proteomic approach was used to compare the membrane-enriched proteins fractions from sessile versus planktonic $S$. frigidimarina with the objective of identifying proteins of $S$. frigidimarina that play a role in adhesion and the early step of biofilm formation.

\section{Results and discussion}

Comparative analysis of adhesion kinetics of $\mathrm{S}$. frigidimarina and $\mathrm{S}$. oneidensis

Because adhesion is a key step of biofilm formation, the adhesion ability of $S$. frigidimarina NCIMB400 was evaluated using a bacterial nucleic acid staining assay adapted from previous studies (Leroy et al., 2007; Camps et al., 2011). PBS and ASW (artifical seawater), two buffered saline (organic free) solutions are often used for adhesion assays (Zampini et al., 2005; Stauder et al., 2010; Camps et al., 2011) to avoid potential bacterial growth over the time of the experiment. Both Shewanella species were unable to grow in ASW and PBS and gave similar results in this adhesion assay (data not shown). The number of adhered bacteria increased with time for both S. frigidimarina NCIMB400 and S. oneidensis MR-1 in ASW (Fig. 1A and B). A saturation of S. frigidimarina adhesion can be observed at $\mathrm{OD}_{600}$ of 0.5 following $5 \mathrm{~h}$ incubation, with no further increase in the number of bacteria adhered to the bottom of the microplates. The most important progression was observed at $\mathrm{OD}_{600} 0.1$ and 0.3 for both Shewanella species. At $\mathrm{OD}_{600} 0.3$, the number of $S$. frigidimarina NCIMB400 adhered to the surface was significantly higher than that of $S$. oneidensis MR-1 at 5, $12,24 \mathrm{~h}(P<0.05, P<0.001$ and $P<0.001$ respectively $)$ but not at $48 \mathrm{~h}$, whereas at $\mathrm{OD}_{600} 0.1$, the difference was significant only at $48 \mathrm{~h}(P<0.05)$ (Fig. 1C). As expected, Pseudomonas aeruginosa PAO1 used as a test control adhered more efficiently at $24 \mathrm{~h}$ than the Shewanella strains (Fig. 1D). Taken together, these results show that $S$. frigidimarina is able to adhere in vitro to microplates in a similar manner than $S$. oneidensis, with a significantly higher number of adhered bacteria for $S$. frigidimarina NCIMB400 at all time points.

Evaluation of biofilm formation of S. frigidimarina and S. oneidensis using the Biofilm Ring Test $\Theta$

The biofilm formation of S. frigidimarina NCIMB400 and S. oneidensis MR-1 was evaluated at different time points, either in Luria-Bertani (LB) broth (rich medium), ASW or PBS (both organic free) solutions for each of the strains using the Biofilm Ring Test ${ }^{\circledR}$ (Fig. 2A-E). The Biofilm Ring Test ${ }^{\circledR}$, an innovative tool allowing the evaluation of biofilm formation based on the motility of inert paramagnetic microbeads, has the advantage of bringing a different approach to study biofilms, focusing rather on density and extracellular networks (Chavant et al., 2007). At most time points (Fig. 2D and E), significantly highest $\triangle \mathrm{BFI}$ (BFI for Biofilm Formation Index) for S. frigidimarina NCIMB400 and S. oneidensis MR-1 were obtained when bacteria were suspended in PBS or ASW but not in LB $(P<0.001)$, suggesting that ASW promotes the formation of biofilm of $S$. frigidimarina NCIMB400 and $S$. oneidensis MR-1, whereas LB represses this ability. The results also show that in ASW, S. frigidimarina biofilm reaches a plateau at $12 \mathrm{~h}$, whereas the progression of biofilm formation is slower for S. oneidensis (Fig. 2B,D and E). The $\triangle \mathrm{BFI}$ of the biofilm formed in ASW at 12 and $24 \mathrm{~h}$ are significantly higher $(P<0.001)$ for $S$. frigidimarina compared with $S$. oneidensis, demonstrating that S. frigidimarina biofilm formation is faster than that of S. oneidensis in ASW. Pseudomonas aeruginosa PAO1, as previously observed (Nagant et al., 2010), show very high $\triangle \mathrm{BFI}$ values at 0 and $5 \mathrm{~h}$ (Fig. $2 \mathrm{~A}-\mathrm{C}$ and data not shown), probably due to a high initial number of adhered bacteria for this strain. Shewanella oneidensis presents the same pattern in LB only, while the $\triangle \mathrm{BFI}$ of $S$. frigidimarina is only positive after $5 \mathrm{~h}$. Taken together, these data indicate that in ASW, S. frigidimarina NCIMB400 is able to form a biofilm faster than S. oneidensis MR-1.

In this experiment, S. frigidimarina biofilm formation was triggered in the ASW and PBS solutions, but not in 
A

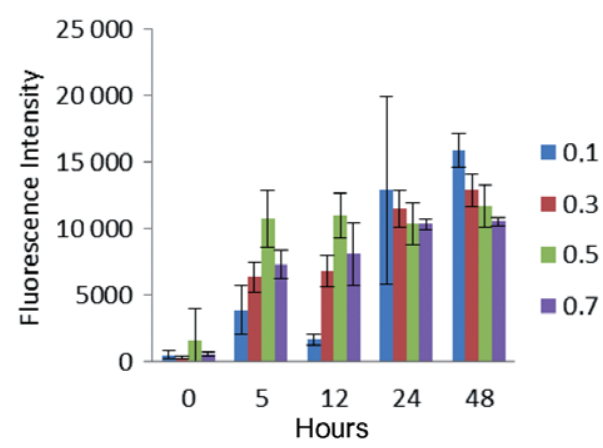

$\mathrm{C}$

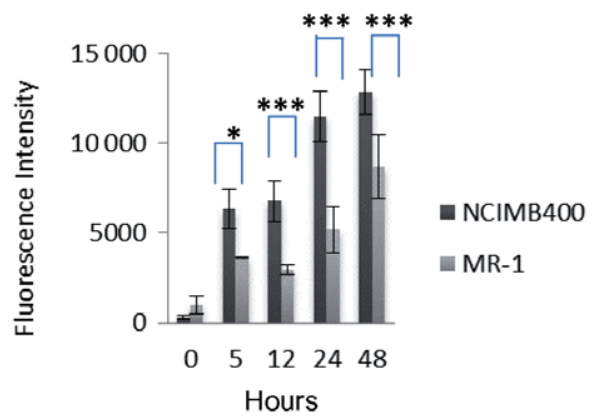

B

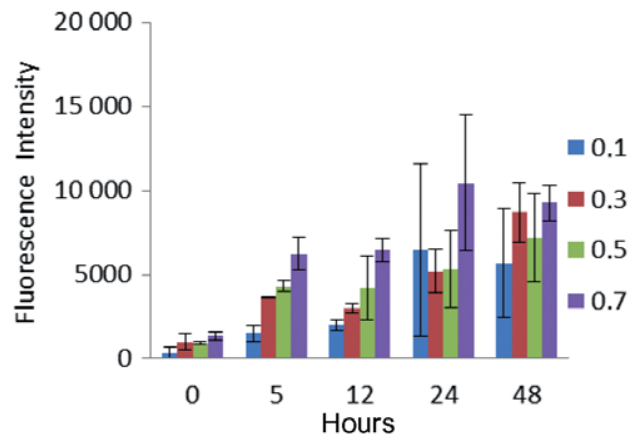

D

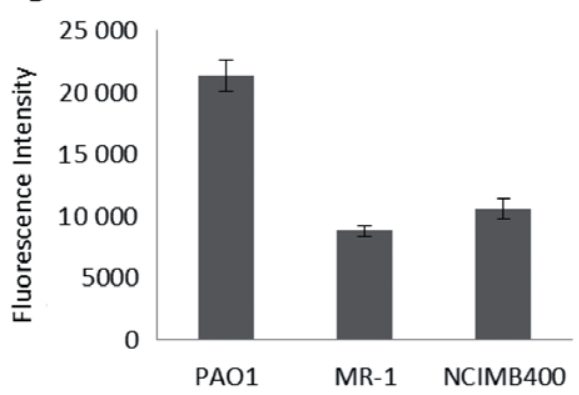

Fig. 1. Adhesion assays of S. frigidimarina NCIMB400. Post-exponential strains of S. frigidimarina NCIMB400, S. oneidensis MR-1 and $P$. aeruginosa PAO1 were inoculated in ASW solution and stained with Syto61. The fluorescence intensity of bacteria adhered at the bottom of the plates was evaluated at $0,5,12,24$ and $48 \mathrm{~h}$. Adhesion of (A) S. frigidimarina and (B) S. oneidensis, inoculated at different concentrations $\left(\mathrm{OD}_{600 \mathrm{~nm}}=0.1,0.3,0.5\right.$ and 0.7$)$; Comparison of $S$. fridigimarina and $S$. oneidensis adhesions $(C)$ when inoculated at an $\mathrm{OD}_{600 \mathrm{~nm}}$ of 0.3 ; adhesion of $S$. frigidimarina compared with that of $S$. oneidensis and of $P$. aeruginosa (D) at $24 \mathrm{~h}$ with an initial $\mathrm{OD}_{600 \mathrm{~nm}}$ of 0.3 . The error bars indicate the standard errors of the means. Statistical significance was accepted at $p<0.05$. ${ }^{*}$ for $p<0.05,{ }^{* *}$ for $p<0.01$ and ${ }^{* * *}$ for $p<0.001$.

LB. LB is a nutrient-rich medium, in which S. frigidimarina and $S$. oneidensis are frequently propagated (as they have no real salt requirement) (Bowman et al., 1997; Bozal et al., 2002). PBS, which has no carbon source and ASW, a sea salt solution, resembling the composition of the salts dissolved in seawater, with bicarbonate as sole carbon source, were used in this assay as nutrient-poor medium. Tween 20 was added to these solutions for the Biofilm Ring Test ${ }^{\circledR}$, at the concentration $0.004 \% \mathrm{w} / \mathrm{v}$, below the inhibiting concentration for growth or biofilm formation (Slijkhuis et al., 1984; Toutain-Kidd et al., 2009; Brian-Jaisson et al., 2014). It is important to note that no bacterial growth was observed at this concentration of Tween in ASW and PBS (data not shown). It has been shown that bicarbonate can be assimilated by numerous heterotrophic or mixotrophic bacteria (DeLorenzo et al., 2012), and Tween 20 can be hydrolysed by both Shewanella strains (Bowman et al., 1997; Bozal et al., 2002). The fact that in PBS (no carbon source), the biofilm formation of $S$. frigidimarina was more important than in LB, suggests that carbonate does not play a role in the biofilm development in this assay for this strain, but it remains to check if Tween does. An earlier study, under nutrient-limiting conditions, also resulted in the formation of a more robust biofilm by S. oneidensis (Thormann et al., 2004). It is known that environmental conditions influence bacterial biofilm formation in different ways. For some bacteria, such as E. coli O157:H7 and Salmonella enterica serovar typhimurium, nutrient limitation triggers the development of biofilm through the stationary-phase sigma factor RpoS activation of biofilm-related genes. Furthermore, under starvation or stress conditions, the extracellular polysaccharides (EPS) composition and biofilm structure have also been shown to be modified (Parsek and Tolker-Nielsen, 2008; Myszka and Czaczyk, 2009). However, in other bacteria, such as Vibrio cholerae, biofilm formation is stimulated by nutrient-rich environments, which are also regulated by RpoS (Dewanti and Wong, 1995; Karatan and Watnick, 2009). Some osmolytes, including $\mathrm{NaCl}$ and/or sucrose, that produce a high osmolarity environment can also inhibit the biofilm formation of $S$. typhymurium (White et al., 2010). Vibrio cholerae can form a biofilm under high-salt solutions, a phenomenon controlled by the regulator OscR (osmolarity controlled regulator), which can modulate gene transcription involved in biofilm matrix production (Karatan and Watnick, 2009; Shikuma and Yildiz, 2009). Therefore, the variation of the response in 
A

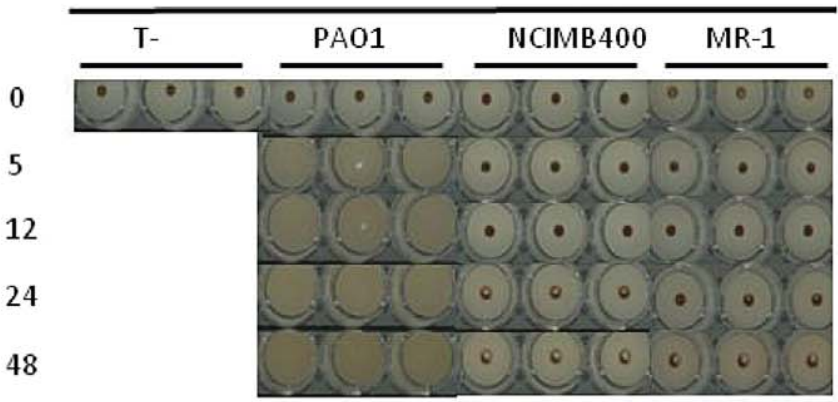

B

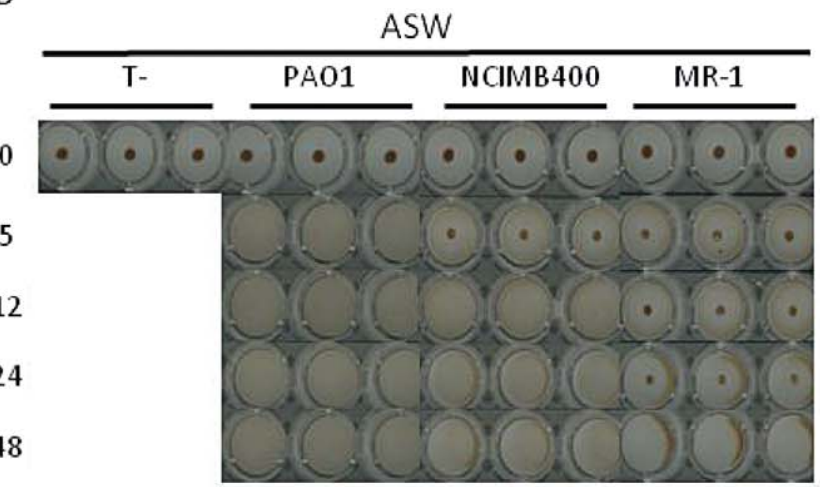

C

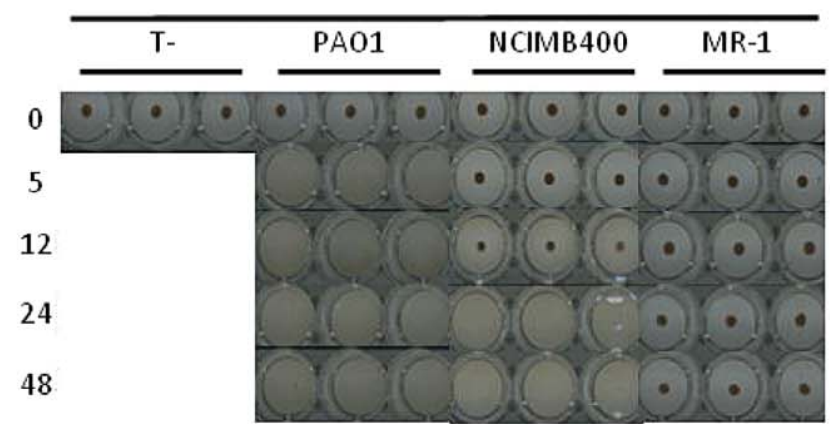

D

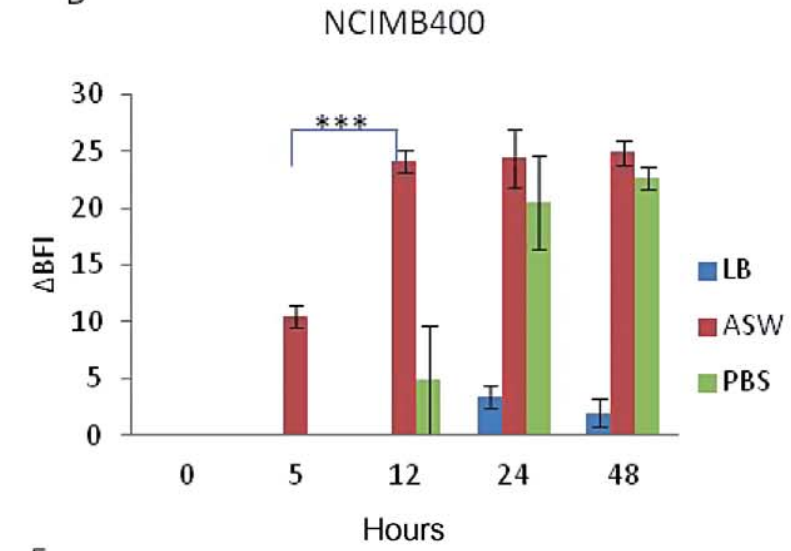

E

MR-1

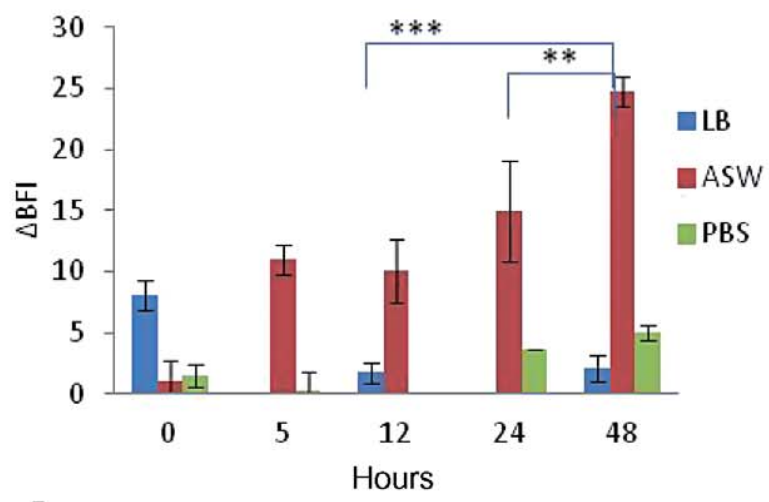

F

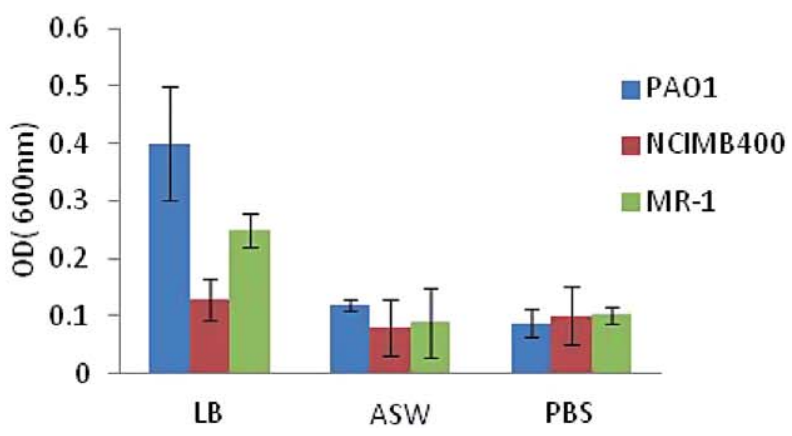

Fig. 2. Biofilm formation of $S$. frigidimarina NCIMB400. Post-exponential cultures of S. frigidimarina NCIMB400, S. oneidensis MR-1 and $P$. aeruginosa PAO1 were incubated in microplates for $0,5,12,24$ or $48 \mathrm{~h}$ in LB, ASW or PBS as shown in the photographs in A, B, C in presence of paramagnetic microbead. After incubation and magnetization of the microplates, mobility of the beads was evaluated using Biofilm Control plate reader. Kinetics of $\triangle \mathrm{BFI}$ (Biofilm Formation Index) are presented in D and $\mathrm{E}$ for NCIMB400 and MR-1 respectively. Bacterial concentrations after biofilm formation have been evaluated at $24 \mathrm{~h}(\mathrm{~F})$. After elimination of supernatants, cells were washed, scraped and re-suspended in sterile LB, ASW or PBS before $\mathrm{OD}_{600}$ was measurement. The error bars indicate the standard errors of the means. Statistical significance was accepted at $p<0.05$. ${ }^{*}$ for $p<0.05,{ }^{* *}$ for $p<0.01$ and ${ }^{* * *}$ for $p<0.001$.

adhesion and biofilm formation in different nutrient-limiting and osmolarity environments may explain the results found for Shewanella sp. using the Biofilm Ring Test ${ }^{\circledR}$. We believe that it is rather exudates (types and density) of the biofilm matrix that are produced in ASW than an increase in bacterial number, which is responsible for the high $\triangle \mathrm{BFI}$ level observed for S. frigidimarina. Studying more precisely which components of the media are responsible for biofilm formation by $S$. frigidimarina would be of interest, in particular what is triggering biofilm formation in ASW and/or what is inhibiting biofilm formation in rich media such as LB. 
To determine if the immobilization of the magnetic beads in the previous assay by $S$. frigidimarina NCIMB400 and S. oneidensis MR-1 in ASW or PBS solutions was due to a higher number of bacteria bound to the surface of the wells or by the biofilm matrix itself, a strip well inoculated in the same conditions was kept to evaluate bacterial concentration for each condition at $24 \mathrm{~h}$. The results in Fig. 2F show that except for $P$. aeruginosa PAO1, the concentrations of resuspended bacteria present in the wells at $24 \mathrm{~h}$ are very close to each other whether LB, ASW or LB was used, using the spectrophotometer and the CFUs numeration (data not shown). No statistical difference was found for $S$. frigidimarina, when comparing these media. This suggests that at $24 \mathrm{~h}$, for $S$. frigidimarina despite significantly different $\triangle \mathrm{BFI}$ in LB, ASW and PBS, the microbeads were trapped in the actual biofilm matrix of $S$. frigidimarina rather than by an increased number of bacteria in the wells. The study of the structural composition of the biofilm matrix formed in ASW should confirm that S. frigidimarina produces more (and/or different) extracellular components in ASW than in LB, as suggested by the results shown in Fig. $2 \mathrm{~F}$.

\section{Proteomic analysis of sessile versus planktonic}

\section{S. frigidimarina}

To compare and identify bacterial membrane proteins involved in adhesion and early biofilm formation, 2D proteomic analysis of adhered versus planktonic S. frigidimarina have been performed in LB broth, its growth medium (Dobbin et al., 1999; Gordon et al., 2000; Reyes-Ramirez et al., 2003). The reasons why we selected LB for this approach are as following: (i) planktonic bacteria cannot be produced in ASW as S. frigidimarina NCIMB400 cannot grow in this solution; (ii) the use of LB limits the upregulation of stress-related genes/proteins and phenotypical modifications due to the change of medium that would be required if we grow first the bacteria in LB and then switch to ASW; (iii) we are rather looking for bacterial surface components involved in adhesion and early steps of biofilm formation than extracellular exudates of the biofilm matrix; (iv) LB provides a similar number of adhered bacteria than in ASW and PBS (Fig. 2F), which means that bacteria develop similar initial strategies to adhere onto a polystyrene surface.

Post-exponential S. frigidimarina NCIMB400 were inoculated in LB medium, either in Petri dishes or in an Erlenmeyer flasks under agitated conditions for $24 \mathrm{~h}$, to constitute respectively the sessile and the planktonic samples to be analysed. It is noteworthy to precise that for the sessile samples, bacteria are inoculated directly into multiples Petri dishes (without agar) in order for the bacte- ria to adhere directly onto the polystyrene surface of the dishes (similar to adhesion and biofilm assays described above). A membrane enrichment step was performed on the pellet following the harvest, and proteins were extracted, quantified and subjected to a $2 \mathrm{D}$ electrophoresis approach using $\mathrm{pH}$ 3-10 or $\mathrm{pH}$ 4-7 IPG (immobilized pH gradient) Strips (Table S1). A total number of 105 and 267 spots were detected with the PDQuest 2D - Analysis software for the non-enriched ( $\mathrm{pH}$ 3-10 linear Ready Strip only) fractions from both planktonic and sessile bacteria respectively. For the membrane-enriched fractions, 167 and 185 spots with the pH 3-10 IPG Strips versus 564 and 416 spots using the 4-7 IPG Strips were found from both planktonic and sessile bacteria respectively (Table S1). The total number of matched spots and the total number of upregulated spots detected in each condition show a higher number of spots in both planktonic and sessile conditions when pH 4-7 IPG Strips was used (Table S1). The $\mathrm{pH} 4-7$ IPS Strips re-centred the spot window in the 2D gels, increasing both resolution and separation of detectable spots (Fig. S1). As a result, using the gels $\mathrm{pH} 4-7,22$ spots in the membrane-enriched fraction from the sessile sample were selected for protein sequencing.

The result of sequencing provided a list of proteins for each spot sequenced (Table 1) corresponding to a specific annotated gene tag in the $S$. frigidimarina NCIMB400 sequenced genome (http://genome.jgi.doe.gov/), including those for uncharacterized proteins. For all these proteins, we checked using the UniProtKB (http://www .uniprot.org/) and NCBI websites that the gene tag corresponded to each protein-coding name. Information given by the gene related to the identified peptides on the annotated sequences genome proved to be very useful to finalize the analysis including for the putative uncharacterized proteins (Table 1). The predicted subcellular localization tool was provided by PSIPREP (http://www.imtech.res.in/raghava/pslpred/submit.html) and PSORTB (http://www.psort.org/psortb/). Among the 22 spots listed in Table 1, at least 12 potential surface or membrane-associated protein candidates were identified along with 10 presumptive cytosolic proteins.

The most striking results of this $2 \mathrm{D}$ proteomic analysis concern the proteins Q080U3, Q080V9 and Q080V1, which according to the genome annotation of $S$. frigidimarina NCIMB400 (http://img.jgi.doe.gov), belong to a gene cluster related to the type $\mathrm{VI}$ secretion system (T6SS). The BLAST of nucleic sequences of all putative components of this T6SS suggests that this T6SS is complete, including all basal core components as found in other bacteria (Filloux et al., 2008; Pukatzki et al., 2009; Barret et al., 2011), and all of these 27 sequences are unique ones in the NCIMB400 genome (Fig. 3). Up to 6 T6SS loci, which are localized in genomic islands acquired by HGT (horizontal gene transfer), have been 


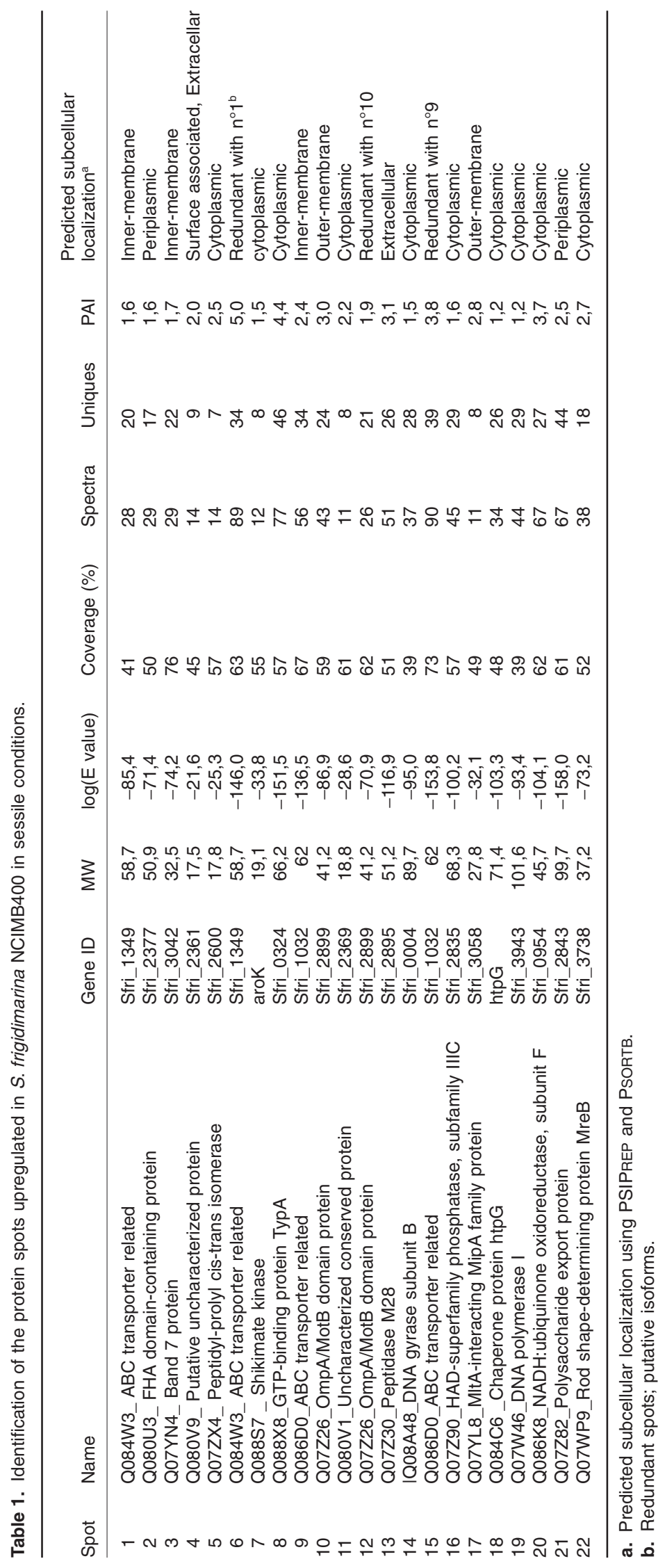




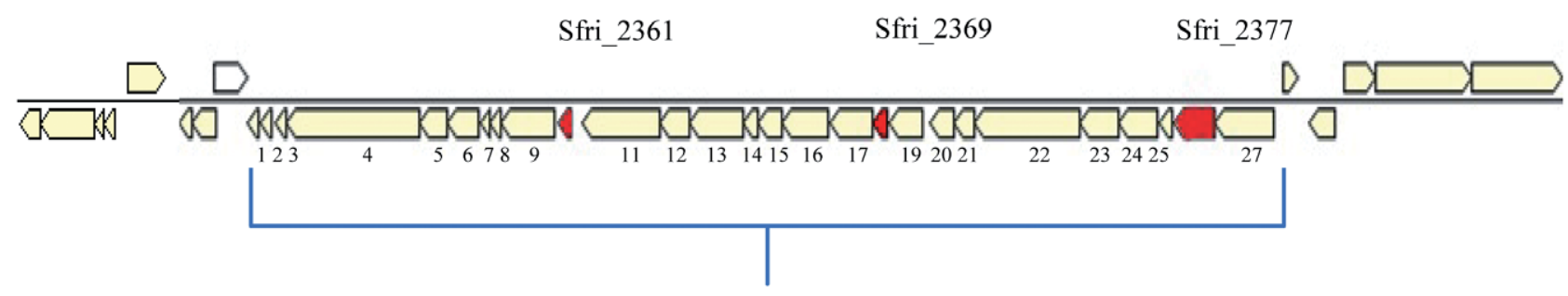

Putative T6SS gene cluster

Fig. 3. T6SS putative gene cluster of S. frigidimarina NCIMB400. The genes Sfri_2361 ( $\left.n^{\circ} 10\right)$, Sri_2369 ( $\left.n^{\circ} 18\right)$ and Sfr_2377 ( $\left.n^{\circ} 26\right)$ are located within a putative T6SS gene cluster in the genome of S. frigidimarina NCIMB400. Annotations in the JGI genome website (http:// img.jgi.doe.gov/) include the following information:

1 (Sfri 2352)-3(Sfri 2354): Hypothetical proteins

4 (Sfri_2355): RHS-repeat associated core domain-containing protein

5 (Sfri_2356)-6 (Sfri_2357): Hypothetical proteins

7 (Sfri_2358): Zn-binding-PAAR domain-containing protein (involved in T6SS)

8 (Sfri_2359): Hypothetical protein

9 (Sfri_2360): T6SS secreted protein VgrG

10 (Sfri_2361): T6SS secreted protein HCP

11 (Sfri_2362): T6SS protein VasG (ATPase, ClpV family protein)

12 (Sfri_2363): T6SS protein ImpH

13 (Sfri_2364): T6SS protein ImpG

14 (Sfri_2365): T6SS protein ImpF

15 (Sfri_2366): T6SS protein ImpE

16 (Sfri_2367): T6SS protein ImpF

17 (Sfri_2368): T6SS protein ImpE

18 (Sfri_2369): T6SS protein ImpD

19 (Sfri 2370): T6SS protein ImpA

20 (Sfri_2371): Protein serine/threonine phosphatase

21 (Sfri_2372): T6SS protein ImpM

22 (Sfri_2373): T6SS protein ImpL(IcmF domain protein)

23 (Sfri_2374): T6SS protein ImpK (OmpA/MotB domain)

24 (Sfri_2375): T6SS protein ImpJ

25 (Sfri_2376): T6SS protein VasD

26 (Sfri_2377): FHA domain-containing protein

27 (Sfri_2378): Serine/threonine protein kinase

found within the same bacterial strains (Barret et al., 2011; De Maayer et al., 2011; Mulder et al., 2012). This recently discovered secretion system has been shown in many Gram-negative bacteria to be involved in bacterial pathogenicity, in inter-bacterial communication, intra- and interspecies competition, biofilm formation and environmental stress response (Sheng et al., 2013; Zhang et al., 2014; Alcoforado Diniz and Coulthurst, 2015; Aragon et al., 2015). Almost no references are available on its link with biofilm formation of marine bacteria (Vaysse et al., 2009; Sheng et al., 2013).

The Sfri_2361 gene (protein Q080V9) is related to the T6SS effector Hcp1 (haemolysin-coregulated protein), as suggested by its annotation (Joint Genome Institute website) and its sequence alignments (NCBI, UniProtKB websites). One key characteristic of T6SS activity is the expression of phage-like proteins Hcp and Vgr (valineglycine-repeat protein) $\mathrm{G} / \mathrm{S}$, part of the contractile sheath and tailspike of the secretion apparatus. They are secreted structural T6SS components (De Maayer et al., 2011; Records, 2011) whose expression can be dependent on experimental conditions in some bacteria (Mulder et al.,
2012). The Hcp protein is secreted by all bacteria with a functional T6SS and has become a reliable indicator of T6SS function, even if its gene is not always found in T6SS loci (Pukatzki et al., 2009). Therefore, it is most likely that the T6SS of $S$. frigidimarina NCIMB400 is functional.

The Sfri_2369 gene corresponds to an uncharacterized protein (Q080V1) orthologous to T6SS impB of the plant symbiont Rhizobium leguminosarum. The locus imp (for impaired in nodulation), comprising the first described genes of T6SS, is essential for nodulation and subsequent stages of symbiosis. The ImpB protein appears to be part of the secretion apparatus across the bacterial membranes, but its exact localization has to be confirmed (Filloux et al., 2008). Analysis of its peptidic sequence using PSLPRED and PSORTB suggests, however, a cytoplasmic localization.

The gene Sfri_2377, which belongs to the same T6SS gene cluster, corresponds to a FHA (forkhead-associated) domain-containing protein (Q080V3), specifically recognizing phosphothreonine residues (Mahajan et al., 2008; Spivey et al., 2011). Some FHA domain-containing proteins have been shown to be present in $A B C$ transporters 
or T6SS components (Bernard et al., 2010). For instance, the fhA1gene of $P$. aeruginosa (PA0081) containing an amino-terminal FHA domain, is part of the Hcp secretion island-I-encoded type VI secretion system (H-T6SS) loci (Boyer et al., 2009). The active form of Fha1 protein is required for secretion of the T6SS substrate Hcp1 (Mougous et al., 2007; Hsu et al., 2009). The activation of the T6SS involves a post-translational regulatory cascade requiring a serine-threonine kinase and a phosphatase for the regulation of the FHA inner membrane protein (Bernard et al., 2010). Interestingly, analysis of the surrounding genes within the T6SS gene cluster of S. frigidimarina NCIMB400 showed the presence of a serine/threonine kinase (Sfr_2378) and a serine/threonine phosphatase (Sfri_2371), upstream and downstream, respectively, of the FHA domain-containing protein (Fig. 3). Although S. frigidimarina T6SS includes approximately 20-27 proteins (Fig. 3), as previously shown in other bacterial T6SS (De Maayer et al., 2011; Mulder et al., 2012), whether this T6SS is functional in the S. frigidimarina NCIMB400 strain and is involved in adhesion and biofilm formation remain to be further investigated. Overall, these results suggest that these three proteins (Q080U3, Q080V9, Q080V1), upregulated in sessile conditions, are part of a same putative T6SS gene cluster in S. frigidimarina NCIMB400.

Among the other interesting candidates potentially involved in adhesion and early biofilm formation, the polysaccharide export protein Q07Z82 is a putative membrane-associated protein that is potentially involved in the export of EPS or capsular polysaccharides that form a layer associated to the cell surface (Cuthbertson et al., 2009). Several Shewanella sp. lipopolysaccharides (LPSs) have been studied, although little is known about the EPS and their export/biogenesis in this genus (Korenevsky et al., 2002). Shewanella oneidensis, Shewanella algae, S. frigidimarina, and Shewanella sp. strain MR-4 possess either O-side chains or capsular fringes, albeit are technically difficult to distinguish. The composition and length of surface polysaccharide polymers could play a role in its ability to adhere to surfaces (Korenevsky et al., 2002; Vinogradov et al., 2005; Kouzuma et al., 2010).

The proteomic analysis of the sessile membrane fraction of S. frigidimarina NCIMB400 reveals two ABC transporter-related proteins, Q084W3 and Q086D0 (Table 1). Transporters with ATP-binding cassette (ABC) are part of a superfamily of ubiquitous proteins located in the periplasm and the inner membrane (as found using PSLPRED and PSORTB) (Davidson and Maloney, 2007; Davidson et al., 2008). It has been reported for instance that transition from reversible to irreversible attachment prior to biofilm formation of $P$. fluorescens involves an ABC transporter LapEBC (Hinsa et al., 2003). The lap mutants are unable to attach in an irreversible way and to form a biofilm including inert surfaces (Hinsa et al., 2003).

The OmpA/MotB domain protein identified in this study (Q07Z26) is usually located in the C-terminal region, and this structure is found in outer membrane proteins of many Gram-negative bacteria, such as the porin-like integral membrane proteins (like OmpA), the small lipidanchored proteins (such as Pal) and MotB, a component of a transmembrane proton channel required for anchoring the stator complex of the flagellar motor to the pepdidoglycan of the bacterial cell wall (Van Way et al., 2000; Dumetz et al., 2007; Goulter et al., 2009). The $\mathrm{N}$-terminal half is variable, although some of the proteins in this group have the OmpA-like transmembrane domain at the $\mathrm{N}$ terminus, which is also the case of Q07Z26. The role of Omp proteins such as E. coli OmpA, in various phenotypes including adhesion and biofilm formation, has been extensively studied. OmpA influences bacterial attachment by modulating Type 1 fimbrial expression (reviewed in Smith et al., 2007, and in Krishnan and Prasadarao, 2012).

qRT-PCR of sessile versus planktonic $\mathrm{S}$. frigidimarina in $L B$ and $A S W$

To verify the results found using the $2 \mathrm{D}$ proteomic analysis on some of the candidates, qRT-PCR was used to analyse gene transcriptional expression of hcp1 (Q080V9; Sfri_2361) and impB (Q080V1; Sfri_2369) both part of the same T6SS gene cluster and the pep gene (Q07Z82; Sfri_2843) corresponding to the polysaccharide export protein. The comparison of their transcription in ASW and in LB (Fig. 4) shows that at least the hop1 gene was significantly upregulated in the LB sessile fraction confirming the result found in the proteomic analysis. The result with the $i m p B$ gene showed the same profile but with no significant difference. The pep gene was also upregulated in LB planktonic and more importantly sessile conditions. As flagella genes and proteins are upregulated in many cases in planktonic compared with sessile conditions (Guttenplan and Kearns, 2013), the flgE gene from the flagella apparatus was used to verify if we would obtain a different pattern. This gene involved in flagella motility was only upregulated in the LB and planktonic fractions. Taken together, these results corroborate the results found with the $2 \mathrm{D}$ proteomic analysis regarding the upregulation of the T6SS functional marker $h c p 1$ as well as of the polysaccharide export protein in LB and sessile conditions. The reason why the $h c p 1$ or pep genes are not upregulated in ASW is not known. However, as said above, the medium and the presence of some osmolytes could modulate the expression of these genes. It is possible that the T6SS (through its involvement in competition) is more relevant for $S$. frigidimarina in rich media and 


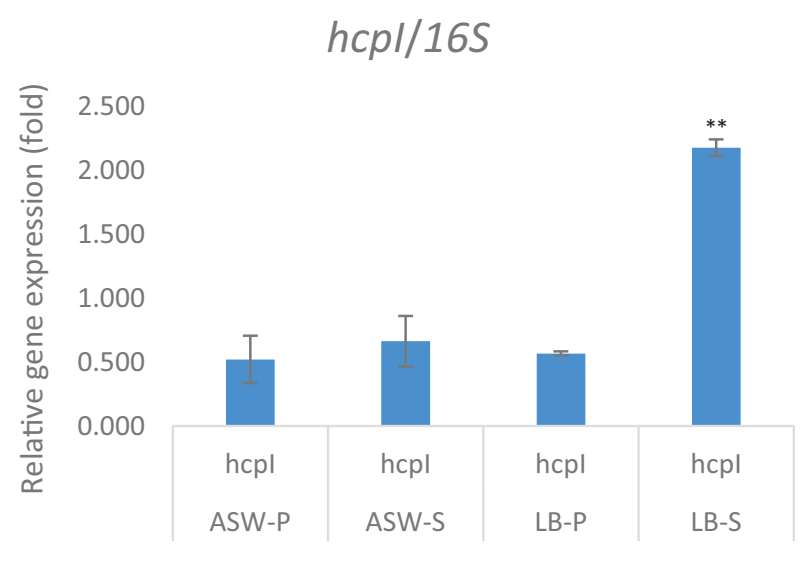

pep/16S

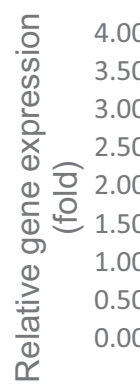

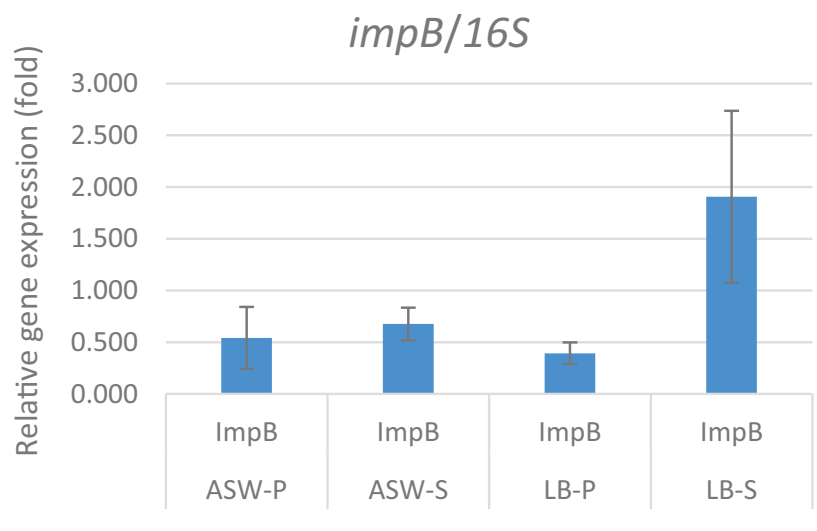

flgE/16S
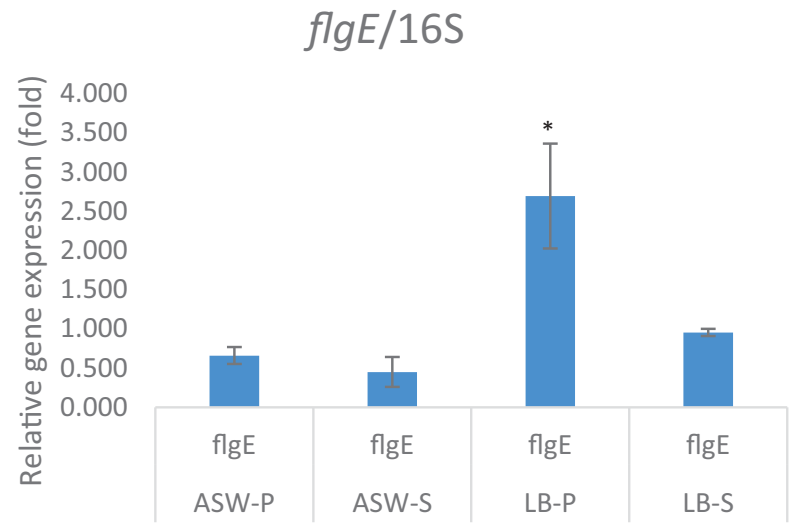

Fig. 4. $\mathrm{qRT}-\mathrm{PCR}$ analysis of $h c p l, i m p B$, pep and flgE transcript levels in S. fridigimarina in the sessile (S) versus planktonic (P) fractions. The samples have been prepared in LB or ASW media. The relative difference has been calculated using the control gene 16S rRNA. Statistical significance was accepted at $p<0.05$. ${ }^{*}$ for $p<0.05,{ }^{* *}$ for $p<0.01$ and ${ }^{* * *}$ for $p<0.001$.

that the pep gene synthetizes a type of polysaccharide that is only produced in LB. Other polysaccharides may be produced in ASW. Pseudomonas aeruginosa is known to produce different types of polysaccharides such as Pel (pellicle) and Psl (polysaccharide synthesis locus). Both are regulated by high level of intracellular c-di-GMP as well as by the stationary-phase $\sigma$-factor RpoS, which induces $p s /$ transcription in response to changes in global physiology (Mann and Wozniak, 2012). The regulation of the T6SS and secretion of polysaccharides are tied to several and complex regulatory networks that remain to be investigated (Bernard et al., 2010). The verification of the actual secretion of Hcp1-like protein by S. fridigimarina NCIMB400 and of pep gene-associated polysaccharides in these media would fully demonstrate the functionality and the regulation of these genes in different situations.

\section{Acknowledgements}

This work was supported by the Université de Toulon research $B Q R$ funding. PVO is the recipient of a French PACA Region doctoral fellowship. The authors wish to thank
Dr. A. Guillot from the PAPPSO platform for protein sequencing from the 2D gel spots and for its assistance. The authors also wish to thank Dr. J. Gralnick from the University of Minnesota, St Paul, MN, USA, for providing the two Shewanella strains, NCIMB400 and MR-1. The authors declare that they have no competing interests.

\section{References}

Alcoforado Diniz, J., and Coulthurst, S.J. (2015) Intraspecies competition in Serratia marcescens is mediated by Type VI-secreted rhs effectors and a conserved effectorassociated accessory protein. J Bacteriol 197: 2350-2360.

Aragon, I.M., Perez-Mendoza, D., Moscoso, J.A., Faure, E., Guery, B., Gallegos, M.T., et al. (2015) Diguanylate cyclase DgcP is involved in plant and human Pseudomonas spp. infections. Environ Microbiol 17: 43324351.

Barret, M., Egan, F., Fargier, E., Morrissey, J.P., and O'Gara, F. (2011) Genomic analysis of the type VI secretion systems in Pseudomonas spp.: novel clusters and putative effectors uncovered. Microbiology 157: 1726-1739.

Bernard, C.S., Brunet, Y.R., Gueguen, E., and Cascales, E. (2010) Nooks and crannies in type VI secretion regulation. J Bacteriol 192: 3850-3860. 
Bowman, J.P., McCammon, S.A., Nichols, D.S., Skerratt, J.H., Rea, S.M., Nichols, P.D., and McMeekin, T.A. (1997) Shewanella gelidimarina sp. nov. and Shewanella frigidimarina sp. nov., novel Antarctic species with the ability to produce eicosapentaenoic acid $(20: 5 \omega 3)$ and grow anaerobically by dissimilatory $\mathrm{Fe}(\mathrm{III})$ reduction. Int $\mathrm{J}$ Syst Bacteriol 47: 1040-1047.

Boyer, F., Fichant, G., Berthod, J., Vandenbrouck, Y., and Attree, I. (2009) Dissecting the bacterial type VI secretion system by a genome wide in silico analysis: what can be learned from available microbial genomic resources? BMC Genomics 10: 104.

Bozal, N., Montes, M.J., Tudela, E., Jimenez, F., and Guinea, J. (2002) Shewanella frigidimarina and Shewanella livingstonensis sp. nov. isolated from Antarctic coastal areas. Int J Syst Evol Microbiol 52: 195-205.

Brian-Jaisson, F., Ortalo-Magne, A., Guentas-Dombrowsky, L., Armougom, F., Blache, Y., and Molmeret, M. (2014) Identification of bacterial strains isolated from the Mediterranean Sea exhibiting different abilities of biofilm formation. Microb Ecol 68: 94-110.

Camps, M., Briand, J.-F., Guentas-Dombrowsky, L., Culioli, G., Bazire, A., and Blache, Y. (2011) Antifouling activity of commercial biocides vs. natural and natural-derived products assessed by marine bacteria adhesion bioassay. Mar Pollut Bull 62: 1032-1040.

Chavant, P., Gaillard-Martinie, B., Talon, R., Hebraud, M., and Bernardi, T. (2007) A new device for rapid evaluation of biofilm formation potential by bacteria. J Microbiol Methods 68: 605-612.

Cuthbertson, L., Mainprize, I.L., Naismith, J.H., and Whitfield, C. (2009) Pivotal roles of the outer membrane polysaccharide export and polysaccharide copolymerase protein families in export of extracellular polysaccharides in gram-negative bacteria. Microbiol Mol Biol Rev 73: 155177.

Davidson, A.L., and Maloney, P.C. (2007) ABC transporters: how small machines do a big job. Trends Microbiol 15: 448-455.

Davidson, A.L., Dassa, E., Orelle, C., and Chen, J. (2008) Structure, function, and evolution of bacterial ATP-binding cassette systems. Microbiol Mol Biol Rev 72: 317-364.

De Maayer, P., Venter, S.N., Kamber, T., Duffy, B., Coutinho, T.A., and Smits, T.H. (2011) Comparative genomics of the Type VI secretion systems of Pantoea and Erwinia species reveals the presence of putative effector islands that may be translocated by the VgrG and Hcp proteins. BMC Genomics 12: 576.

De Vriendt, K., Theunissen, S., Carpentier, W., De Smet, L., Devreese, B., and Van Beeumen, J. (2005) Proteomics of Shewanella oneidensis MR-1 biofilm reveals differentially expressed proteins, including AggA and RibB. Proteomics 5: 1308-1316.

DeLorenzo, S., Brauer, S.L., Edgmont, C.A., Herfort, L., Tebo, B.M., and Zuber, P. (2012) Ubiquitous dissolved inorganic carbon assimilation by marine bacteria in the Pacific Northwest coastal ocean as determined by stable isotope probing. PLoS ONE 7: e46695.

Dewanti, R., and Wong, A.C. (1995) Influence of culture conditions on biofilm formation by Escherichia coli O157:H7. Int J Food Microbiol 26: 147-164.
Dobbin, P.S., Butt, J.N., Powell, A.K., Reid, G.A., and Richardson, D.J. (1999) Characterization of a flavocytochrome that is induced during the anaerobic respiration of $\mathrm{Fe} 3+$ by Shewanella frigidimarina NCIMB400. Biochem J 342 (Part 2): 439-448.

Doghri, I., Rodrigues, S., Bazire, A., Dufour, A., Akbar, D., Sopena, V., et al. (2015) Marine bacteria from the French Atlantic coast displaying high forming-biofilm abilities and different biofilm 3D architectures. BMC Microbiol 15: 231.

Dumetz, F., Lapatra, S.E., Duchaud, E., Claverol, S., and Le Henaff, M. (2007) The Flavobacterium psychrophilum OmpA, an outer membrane glycoprotein, induces a humoral response in rainbow trout. J Appl Microbiol 103: 1461-1470.

Filloux, A., Hachani, A., and Bleves, S. (2008) The bacterial type VI secretion machine: yet another player for protein transport across membranes. Microbiology 154: 15701583.

Fredrickson, J.K., Romine, M.F., Beliaev, A.S., Auchtung, J.M., Driscoll, M.E., Gardner, T.S., et al. (2008) Towards environmental systems biology of Shewanella. Nat Rev Microbiol 6: 592-603.

Gerlach, R.G., and Hensel, M. (2007) Protein secretion systems and adhesins: the molecular armory of Gramnegative pathogens. Int J Med Microbiol 297: 401-415.

Gordon, E.H., Pike, A.D., Hill, A.E., Cuthbertson, P.M., Chapman, S.K., and Reid, G.A. (2000) Identification and characterization of a novel cytochrome c(3) from Shewanella frigidimarina that is involved in $\mathrm{Fe}(\mathrm{III})$ respiration. Biochem J 349: 153-158.

Goulter, R.M., Gentle, I.R., and Dykes, G.A. (2009) Issues in determining factors influencing bacterial attachment: a review using the attachment of Escherichia coli to abiotic surfaces as an example. Lett Appl Microbiol 49: 1-7.

Guttenplan, S.B., and Kearns, D.B. (2013) Regulation of flagellar motility during biofilm formation. FEMS Microbiol Rev 37: 849-871.

Hau, H.H., and Gralnick, J.A. (2007) Ecology and biotechnology of the genus Shewanella. Annu Rev Microbiol 61: 237-258.

Hinsa, S.M., Espinosa-Urgel, M., Ramos, J.L., and O'Toole, G.A. (2003) Transition from reversible to irreversible attachment during biofilm formation by Pseudomonas fluorescens WCS365 requires an ABC transporter and a large secreted protein. Mol Microbiol 49: 905-918.

Hsu, F., Schwarz, S., and Mougous, J.D. (2009) TagR promotes PpkA-catalysed type VI secretion activation in Pseudomonas aeruginosa. Mol Microbiol 72: 11111125.

Huggett, M.J., Williamson, J.E., de Nys, R., Kjelleberg, S., and Steinberg, P.D. (2006) Larval settlement of the common Australian sea urchin Heliocidaris erythrogramma in response to bacteria from the surface of coralline algae. Oecologia 149: 604-619.

Karatan, E., and Watnick, P. (2009) Signals, regulatory networks, and materials that build and break bacterial biofilms. Microbiol Mol Biol Rev 73: 310-347.

Korenevsky, A.A., Vinogradov, E., Gorby, Y., and Beveridge, T.J. (2002) Characterization of the lipopolysaccharides and capsules of Shewanella spp. App Environ Microbiol 68: 4653-4657. 
Kouzuma, A., Meng, X.Y., Kimura, N., Hashimoto, K., and Watanabe, K. (2010) Disruption of the putative cell surface polysaccharide biosynthesis gene SO3177 in Shewanella oneidensis MR-1 enhances adhesion to electrodes and current generation in microbial fuel cells. Appl Environ Microbiol 76: 4151-4157.

Krishnan, S., and Prasadarao, N.V. (2012) Outer membrane protein A and OprF: versatile roles in Gram-negative bacterial infections. FEBS J 279: 919-931.

Learman, D.R., Yi, H., Brown, S.D., Martin, S.L., Geesey, G.G., Stevens, A.M., and Hochella, M.F., Jr (2009) Involvement of Shewanella oneidensis MR-1 LuxS in biofilm development and sulfur metabolism. Appl Environ Microbiol 75: 1301-1307.

Lee, J.V., Gibson, D.M., and Shewan, J.M. (1977) A numerical taxonomic study of some Pseudomonas-like marine bacteria. J Gen Microbiol 98: 439-451.

Leroy, C., Delbarre-Ladrat, C., Ghillebaert, F., Rochet, M.J., Compère, C., and Combes, D. (2007) A marine bacterial adhesion microplate test using the DAPI fluorescent dye: a new method to screen antifouling agents. Lett Appl Microbiol 44: 372-378.

Mahajan, A., Yuan, C., Lee, H., Chen, E.S.-W., Wu, P.-Y., and Tsai, M.-D. (2008) Structure and function of the phosphothreonine-specific FHA domain. Sci Signal 1: re12.

Mann, E.E., and Wozniak, D.J. (2012) Pseudomonas biofilm matrix composition and niche biology. FEMS Microbiol Rev 36: 893-916.

Mougous, J.D., Gifford, C.A., Ramsdell, T.L., and Mekalanos, J.J. (2007) Threonine phosphorylation post-translationally regulates protein secretion in Pseudomonas aeruginosa. Nat Cell Biol 9: 797-803.

Mulder, D.T., Cooper, C.A., and Coombes, B.K. (2012) Type VI secretion system-associated gene clusters contribute to pathogenesis of Salmonella enterica serovar Typhimurium. Infect Immun 80: 1996-2007.

Myszka, K., and Czaczyk, K. (2009) Characterization of adhesive exopolysaccharide (EPS) produced by Pseudomonas aeruginosa under starvation conditions. Curr Microbiol 58: 541-546.

Nagant, C., Tre-Hardy, M., Devleeschouwer, M., and Dehaye, J.P. (2010) Study of the initial phase of biofilm formation using a biofomic approach. J Microbiol Methods 82: 243-248.

Paquete, C.M., Saraiva, I.H., Calcada, E., and Louro, R.O. (2010) Molecular basis for directional electron transfer. $J$ Biol Chem 285: 10370-10375.

Parsek, M.R., and Tolker-Nielsen, T. (2008) Pattern formation in Pseudomonas aeruginosa biofilms. Curr Opin Microbiol 11: $560-566$.

Patel, P., Callow, M.E., Joint, I., and Callow, J.A. (2003) Specificity in the settlement - modifying response of bacterial biofilms towards zoospores of the marine alga Enteromorpha. Environ Microbiol 5: 338-349.

Pukatzki, S., McAuley, S.B., and Miyata, S.T. (2009) The type VI secretion system: translocation of effectors and effectordomains. Curr Opin Microbiol 12: 11-17.

Records, A.R. (2011) The type VI secretion system: a multipurpose delivery system with a phage-like machinery. Mol Plant Microbe Interact 24: 751-757.
Reyes-Ramirez, F., Dobbin, P., Sawers, G., and Richardson, D.J. (2003) Characterization of transcriptional regulation of Shewanella frigidimarina $\mathrm{Fe}$ (III)-induced flavocytochrome c reveals a novel iron-responsive gene regulation system. $J$ Bacteriol 185: 4564-4571.

Sheng, L., Lv, Y., Liu, Q., Wang, Q., and Zhang, Y. (2013) Connecting type VI secretion, quorum sensing, and c-diGMP production in fish pathogen Vibrio alginolyticus through phosphatase PppA. Vet Microbiol 162: 652-662.

Shikuma, N.J., and Yildiz, F.H. (2009) Identification and characterization of OscR, a transcriptional regulator involved in osmolarity adaptation in Vibrio cholerae. J Bacteriol 191: 4082-4096.

Slijkhuis, H., van Groenestijn, J.W., and Kylstra, D.J. (1984) Microthrix parvicella, a filamentous bacterium from activated sludge: growth on Tween 80 as carbon and energy source. J Gen Microbiol 130: 2035-2042.

Smith, S.G., Mahon, V., Lambert, M.A., and Fagan, R.P. (2007) A molecular Swiss army knife: ompa structure, function and expression. FEMS Microbiol Lett 273: 1-11.

Spivey, V.L., Molle, V., Whalan, R.H., Rodgers, A., Leiba, J., Stach, L., et al. (2011) Forkhead-associated (FHA) domain containing $\mathrm{ABC}$ transporter Rv1747 is positively regulated by Ser/Thr phosphorylation in Mycobacterium tuberculosis. J Biol Chem 286: 26198-26209.

Stauder, M., Vezzulli, L., Pezzati, E., Repetto, B., and Pruzzo, C. (2010) Temperature affects Vibrio cholerae O1 El Tor persistence in the aquatic environment via an enhanced expression of GbpA and MSHA adhesins. Environ Microbiol Rep 2: 140-144.

Stin, O.C., Carnahan, A., Singh, R., Powell, J., Furuno, J.P., Dorsey, A., et al. (2003) Characterization of microbial communities from coastal waters using microarrays. Environ Monit Assess 81: 327-336.

Thormann, K.M., Saville, R.M., Shukla, S., Pelletier, D.A., and Spormann, A.M. (2004) Initial Phases of biofilm formation in Shewanella oneidensis MR-1. J Bacteriol 186: 8096-8104.

Toutain-Kidd, C.M., Kadivar, S.C., Bramante, C.T., Bobin, S.A., and Zegans, M.E. (2009) Polysorbate 80 inhibition of Pseudomonas aeruginosa biofilm formation and its cleavage by the secreted lipase LipA. Antimicrob Agents Chemother 53: 136-145.

Van Way, S.M., Hosking, E.R., Braun, T.F., and Manson, M.D. (2000) Mot protein assembly into the bacterial flagellum: a model based on mutational analysis of the motB gene. J Mol Biol 297: 7-24.

Vanrobaeys, F., Devreese, B., Lecocq, E., Rychlewski, L., De Smet, L., and Van Beeumen, J. (2003) Proteomics of the dissimilatory iron-reducing bacterium Shewanella oneidensis MR-1, using a matrix-assisted laser desorption/ ionization-tandem-time of flight mass spectrometer. Proteomics 3: 2249-2257.

Vaysse, P.J., Prat, L., Mangenot, S., Cruveiller, S., Goulas, P., and Grimaud, R. (2009) Proteomic analysis of Marinobacter hydrocarbonoclasticus SP17 biofilm formation at the alkane-water interface reveals novel proteins and cellular processes involved in hexadecane assimilation. Res Microbiol 160(10): 829-837

Vinogradov, E., Nossova, L., Korenevsky, A., and Beveridge, T.J. (2005) The structure of the capsular polysaccharide of 
Shewanella oneidensis strain MR-4. Carbohydr Res 340: 1750-1753.

White, A.P., Weljie, A.M., Apel, D., Zhang, P., Shaykhutdinov, R., Vogel, H.J., and Surette, M.G. (2010) A global metabolic shift is linked to Salmonella multicellular development. PLOS ONE 5: e11814.

Yebra, D.M., Kill, S., and Dam-Johansen, K. (2004) Antifouling technology-past, present and future steps towards efficient and environmentally friendly antifouling coatings. Prog Org Coat 50: 75-104.

Zampini, M., Pruzzo, C., Bondre, V.P., Tarsi, R., Cosmo, M., Bacciaglia, A., et al. (2005) Vibrio cholerae persistence in aquatic environments and colonization of intestinal cells: involvement of a common adhesion mechanism. FEMS Microbiol Lett 244: 267-273.

Zhang, L., Xu, J., Xu, J., Zhang, H., He, L., and Feng, J. (2014) TssB is essential for virulence and required for type VI secretion system in Ralstonia solanacearum. Microb Pathog 74: 1-7.

Zhang, M., Ginn, B.R., Dichristina, T.J., and Stack, A.G. (2010) Adhesion of Shewanella oneidensis MR-1 to iron
(Oxy)(Hydr)oxides: microcolony formation and isotherm. Environ Sci Technol 44: 1602-1609.

\section{Supporting information}

Additional Supporting Information may be found in the online version of this article at the publisher's web-site:

Figure S1. 2D polyacrylamide gels of planktonic and sessile membrane protein enriched fractions from $S$. frigidimarina NCIMB400, performed using $\mathrm{pH}$ 3-10 (A and $\mathrm{B}$ ) or $\mathrm{pH} 4-7$ IPG strips (C and D). Upregulated spots obtained under sessile conditions ( $B$ and $D$ ) are indicated by arrows. Spot numbers in $\mathrm{D}$ correspond to those displayed in Table 1. The $\mathrm{pl}$ and molecular weight (MW) scales are indicated for the horizontal and vertical axis, respectively.

Table S1. Number of protein spots of non-soluble and membrane-enriched fractions, separated by 2D eletrophoresis comparing planktonic and sessile conditions. 